\title{
En relación a las vías romanas y mansiones del territorio provincial de Albacete
}

\author{
G. Carrasco Serrano *
}

\begin{abstract}
RESUMEN
ABSTRACT

Las fuentes antiguas itinerarias que proporcionan datos sobre las comunicaciones romanas del área geográfica correspondiente al actual territorio provincial de Albacete son, el

Itinerario de Antonino, los Vasos de

Vicarello y el Anónimo de Rávena.

Pero a estas vías mencionadas en dichas fuentes, habrá que añadir otros trazados no atestiguados en los itinerarios de época clásica, como es el caso de la ruta Corduba-Saguntum, y cuyo estudio arqueológico permitirá ir completando el sistema de comunicaciones en época romana de este ámbito territorial, cuya situación le convertirá en zona de paso obligado entre la costa, el interior y la alta Andalucía.

The sources of old itineraries that provide information on the Roman communications within the geographical area corresponding today to the province of Albacete are: the Antonino Itinerary, the Vicarello Vases and the Anonymous of Ravena. But apart from the routes mentioned in these sources, there are others not included in the itineraries of the classic period, such as the Corduba-

Saguntum route, an archeological study of which will provide further knowledge of the system of communications that existed in Roman times in this territory, the location of which makes it a natural passage between the coast, inland and upper Andalucia.
\end{abstract}

El propósito del presente trabajo, se ha centrado fundamentalmente en el estudio de aquellas vías y mansiones romanas, constatadas en las an-

* Universidad de Castilla-La Mancha. 
tiguas fuentes itinerarias, relativas al actual área geográfica de la provincia de Albacete, ámbito éste de gran interés en el panorama viario como zona puente entre el Levante y el interior peninsular.

\section{ITINERARIO DE ANTONINO}

A pesar de los diversos problemas que plantea, viene a constituir el Itinerario de Antonino ', la fuente itineraria antigua, sin duda, de más relieve. Pues bien, entre las vías citadas en dicha obra, la denominada Item a Laminio alio itinere Caesarea Augusta transcurría parte su trazado por el territorio provincial de Albacete.

\section{Item a Laminio alio itinere Caesarea Augusta}

Es denominada por E. Saavedra ${ }^{2}$ con el número 31 , Item a Laminio alio itinere Caesaraugustam, lo mismo que Wesseling. Se trata de una segunda ruta dada por el Itinerario para comunicar Laminio con Caesaraugusta frente a It. Ant., 445, 4-446, 2, estando compuesta por varios tramos perfectamente determinados. La longitud total asignada es de CCXLVIIII m.p., que junto a la exacta localización de las diversas mansiones, constituyen los principales problemas a resolver ${ }^{3}$.

\footnotetext{
1 Edición básica de esta obra fue la realizada por P. WESSELING, Vetera Romanorum Itineraria, Amsterdam, 1735. Posteriores y más utilizadas son las de G. PARTHEY et M. PINDER, Itinerarium Antonini Augusti et Hierosolymitanum ex libris manuscriptis, Berlin, 1848, y la de O. CUNTZ, Itineraria Romana, vol. I, Leipzig, 1929. Véase además K. MILLER, Itineraria Romana. Römische Reisewege an der Hand der Tabula Peutingeriana, Stuttgart, 1916; E. SAAvedra, Discursos leidos ante la Real Academia de la Historia, Madrid, 1862; A. BLAZQUEZ, "Nuevo estudio sobre el Itinerario de Antonino", BRAH, 31, 1892. Ya más recientemente J.M. ROLDÁN HERVÁS, Itineraria Hispana. Fuentes antiguas para el estudio de las vias romanas en la Peninsula lbérica, Valladolid-Granada, 1975.

Discursos..., op. cit., pág. 77

Véase en relación a esta via: F. COELLO, "Via romana de Chinchilla a Zaragoza", BRAH, 24, 1894; Id., "Caminos romanos de la provincia de Cuenca», BRAH, 31, 1897; MJSEA, 40, 1921; MJSEA, 52, 1923; ME, 3, 1963; ME, 6, 1964; ME, 11, 1966; M. CORCHADO, "Estudio sobre vías romanas entre el Tajo y el Guadalquivir", AEArq., 42, 1969; J.R. ROLdAN HERvÁs, Itineraria Hispana..., op. cit., págs. 94-95; J.M. ABASCAL, Vias de comunicación romanas de la provincia de Guadalajara, Guadalajara, 1982, págs. 66 y ss.; S. PALOMERO, Las vias romanas de la provincia de Cuenca, Cuenca, 1987, págs. 135 y ss.; G. ARIAS, Repertorio de caminos de la Hispania romana, 1987, págs. 131 y ss.; $M E, 16,1988 ; M E, 17,1988 ; M E, 25,1990 ; M E, 35,1991 ; M E, 39-41$, 1992; ME, 58, 1996; ME, 59, 1996; ME, 61, 1997; ME, 62, 1997; ME, 67, 1998; R. Sanz Gamo, Cultura ibérica y romanización en tierras de Albacete: los siglos de transición, Albacete, 1997, págs. 249-253.
} 
El desarrollo de esta vía, a su paso por el ámbito geográfico objeto de estudio, es descrita en la edición utilizada ${ }^{4}$, de la forma siguiente:

$\begin{array}{rll}446,8 & \begin{array}{l}\text { Item a Lami- } \\ \text { nio alio iti- } \\ \text { nere Caesa- } \\ \text { rea } \\ \text { Augusta }\end{array} & \\ 9 & \text { m.p. CCXLVIIII } \\ & \text { sic: } \\ 10 & \begin{array}{l}\text { Caput flumi- } \\ \text { nis Anae } \\ \text { Libisosia }\end{array} & \text { m.p. VII } \\ 11 & \begin{array}{l}\text { m.p. XIIII } \\ \text { Parietinis }\end{array} & \text { m.p. XXII } \\ 1 & \text { Saltici } & \text { m.p. XVI }\end{array}$

\section{Mansiones}

Caput Fluminis Anae

Distante según indica el Itinerario de Antonino VII m.p., de Laminio, y XIIII m.p., de Libisosia (Libisosa-m: V. de Vicarello), su identificación se relaciona con su propio nombre. No obstante M. Cortés y López ${ }^{5}$ opina que la cabeza o principio del Anas se encontraba en la localidad de Fuenllana. Por su parte $F$. Fita afirma que estaba «... junto al nacimiento del Guadiana, cerca de la Osa de Montiel» ${ }^{6}$. Igualmente para A. FernándezGuerra $^{7}$ se situaría "... muy cerca y al occidente de la Osa de Montiel", de la misma manera que para $\mathrm{E}$. Saavedra ${ }^{8}$. También K. Miller ${ }^{9}$, la coloca en el nacimiento del Guadiana, opinión seguida por J.M. Roldán Hervás ${ }^{10}$ más recientemente.

4 Itineraria Romana. Volumen Prius: Itineraria Antonini Augusti et Burdigalense, Edidit 0 . Cuntz, Leipzig, 1929. En el aparato crítico de esta edición se hace constar: 446,8 liminio $B$ itenere $L$; 9 augustam $L R$ hic $X$ super sunt in marg. $B$; ante 447,1 parietinis eras. $L ; 2 \times V B \times V I R$.

M. CORTÉS y LOPEZ, Diccionario geográfico-histórico de la España Antigua, T. II, Madrid, 1836, pág. 296.

5 Vid., BRAH, XLII, 1903, pág. 283.

Obras de Quevedo, T. II, vol. XLVIII, de B.A.C., Madrid, 1951, pág. 658.

9 E. SaAvedra, Discursos..., op. cit, pág. 90.

Römische Reisewege..., op. cit., col. 163.

10 Itineraria Hispana... op. cit., pág. 228. Por su parte G. ARIAS supone Caput fluminis Anae = Munera (Albacete), vid., $M E, 16,1988$, pág. 3 y $M E, 41,1992$, pág. 9. 
Además del Itinerario de Antonino $(446,11)$, es citada en los Vasos de Vicarello (I: Libisosam; II, III y IV: Libisosa) entre Mentesa y Parietinis, y por el Anónimo de Rávena $(313,14)$ con el nombre de Lebinosa ${ }^{11}$. También es mencionada por otras fuentes antiguas como Ptolomeo (II, 6,

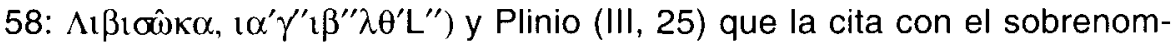
bre de Foroaugustana, habiendo obtenido según este mismo autor clásico, derecho itálico (... ex Libisosana cognomine Foroaugustana, quibus duabus ius Italiae datum). Fue fundación colonial augustea ${ }^{12}$ según se desprende del propio cognomen dado por Plinio. Está asimismo atestiguada epigráficamente como colonia Libisosanorum a través de la inscripción CIL, II, 3234 fechada en el 166 d.C. ${ }^{13}$, pudiéndose constatar también mediante la epigrafía (CIL, II, 4254) ${ }^{14}$ la pertenencia de sus ciudadanos a la tribu Galeria ${ }^{15}$.

11 En relación a la organización viaria en el territorio del entorno a Libisosa, vid., R. Corzo SÁNCHEZ, "In finibus emeritensium", Augusta Emerita, Madrid, 1976, págs. 228-229.

12 Vid., F. VITTINGHOFF, Römische Kolonisation und Bürgerrechtspolitik unter Caesar und Augustus, Mainz, 1951, pág. 107; A. GARCiA BELLIDO, "Las colonias romanas de Hispania", AHDE, 24, 1959, págs. 494-5; Id., "Aportaciones al proceso de romanización del S.E. de la Península", Homenaje a $C$. de Mergelina, Murcia, 1962, pág. 371; H. Galsterer, Untersuchungen zum römischen Städtwesen aut der Iberischen Halbinsel, Berlin, 1971, pág. 71; P.A. BruNT, Italian Manpower 225 A.C.-A.D. 14, Oxford, 1971, pág. 587; B. GalsterER-KRölL, "Untersuchungen zu den Beinamen der Städte des Imperium Romanum", en Epigraphische Studien, 9, 1972, pág. 113. n. ${ }^{\circ} 189 ;$ J. M. a BlAzqueZ, "Ciudades hispanas de la época de Augusto", Symposion de ciudades augusteas, I, Zaragoza, 1976, pág. 116; J.N. BONNEVILLE et alii, "Les villes romaines de la Péninsule Ibérique", Les Villes dans le monde lberique, Paris, 1982, pág. 15; G. ALFÖDY, Römisches Städtewesen auf der neukastilischen Hochebene, Heidelberg, 1987, págs. 31-32; J. M. "Solana SaINz, "Colonización y municipalización bajo César y Augusto: Hispania Citerior", Aspectos de la colonización y municipalización de Hispania, Mérida, 1989, pág. 85; J.M. ABASCAL, U. Espinosa, La ciudad hispano-romana: privilegio y poder, Logroño, 1989, pág. 65; J.C. OLIVARES PEDRENo, Conflicto político y promoción juridica de comunidades en el Occidente romano (133 a.C. -74 d.C.). Alicante, 1998 , pág. 217.

13 CIL, II, 3234: IMP.CAES.DIVI.ANTO/NINI.FILIO.DIVI.HA/DRIANI.NEPOTI.DI/VI. TRAIANI.PARTH.PRON/ DIVI.NERVAE.ABNEPOTI/ M.AURELIO.ANTONINO/AUG.ARMENIA-CO P. M./T.P.XX.IMP.III.COS.III/COLONIA.LIBISOSANORUM. También cf. J. VIVES, Inscripciones latinas de la España Romana, Barcelona, 1971, pág. 132, n. ${ }^{\circ}$ 1133; J.M. ABASCAL PALAzON, Inscripciones romanas de la provincia de Albacete, Albacete, 1990, págs. 43-44.

CIL, II, 4254: P.H.C/ C.VIBIO.C.F/ GAL.PORCIANO/ QUINTIO.ITALICIA/ NO.LIBISOSANO/ EQUO.P.DONATO.A.DIVO/HADRIANO.OMNIB.HO/NORIB.IN.RE.PVBLICASUA. FUNCTO.FLAM./P.H.C.; cf., J. VIVES, Inscripciones latinas..., op. cit, pág. 188, n. ${ }^{\circ} 1617$; G. AlfoldY, Flamines provinciae Hispaniae citerioris, Madrid, 1973, pág. 91, n. ${ }^{\circ} 70$; Id., Die römischen Inschriften von Tarraco, Berlin, 1975, pág. 172, n. ${ }^{\circ} 313$; también vid., R. ETIENNE, Le culte impérial dans la Péninsule Ibérique d'Auguste a Dioclétien. París, 1958, págs. 132 y 139.

Vid., W. KuBITSCHEK, De romanorum tribuum origine ac propagatione, Wien, 1882, págs. 175-176; Id., Imperium romanum tributim discriptum, Wien, 1889, págs. 196-197; R. WIEGELS, Die Tribusinschriften des römischen Hispanien, Berlín, 1985, pág. 120. 
Resulta prácticamente unánime su localización en torno a Lezuza ${ }^{16}$, desde E. Flórez ${ }^{17}$, J. Lozano ${ }^{18}$, M. Cortés y López ${ }^{19}$ y J.A. Ceán Bermúdez ${ }^{20}$; igualmente mantienen dicha ubicación A. Fernández Guerra ${ }^{21}$, E. Saavedra ${ }^{22}$, E. Hübner ${ }^{23}, \mathrm{~F}$. Coello ${ }^{24}$ y K. Miller ${ }^{25}$ entre otros ${ }^{26}$, y ya más recientemente A. García Bellido ${ }^{27}$ para quien el actual nombre sería corrupción del antiguo ${ }^{28}$, J.M. Roldán Hervás ${ }^{29}, \mathrm{G}$. Alföldy ${ }^{30}$, y A. Tovar $^{31}$. Diversos hallazgos arqueológicos ${ }^{32}$ vienen por su parte a apoyar dicha localización.

16 Según P. Silliéres en el cerro del Castillo, junto a la población, vid., "Le Camino de Anibal. Itineraire de gobelets de Vicarello, de Castulo à Saetabis", MCV, 13, 1977, págs. 63 y 75; Id., Les voies de communication de l'Hispanie meridionale, París, 1990, pág. 273.

17 E. FLóeZ, España Sagrada, XXIV, pág. 177.

18 J. Lozano, Bastitania y Contestania del reyno de Murcia, con los vestigios de sus ciudades subterráneas, Murcia, 1794, disert. II, pág. 16.

19 M. CORTÉs y LóPEz, Diccionario geográfico-histórico..., op. cit., T. III, págs. 134-135.

20 J.A. CEÁN BERMúdez, Sumario de las antigüedades romanas que hay en España, Madrid, 1832, pág. 86.

21 Op cit., pág. 658; Id., Discurso leido ante la Real Academnia de la Historia, Madrid, 1875, pág. 122

22 E. SaAvedra, Discursos..., op. cit., pág. 97.

23 Vid., CIL, II, pág. 434.

24 F. COELLO, "Vía romana...", art. cit., pág. 6.

25 Römische Reisewege..., col. 181; vid., también R. Grosse, RE, Suppl. IX, 1962, col. 389.

26 Véase, N. Blanch É Illa, Crónica de la Provincia de Albacete, Albacete, 1866, pág. $15 ; \mathrm{J}$. Roa Erostarbe, Crónica de la Provincia de Albacete, vol. II, Albacete, 1894, pág. 445.

27 A. GARCIA BELLIDO, La España del siglo primero de nuestra Era, Madrid, 1947, păg. 238; Id., La Península lbérica en los comienzos de su historia, Madrid, 1953, págs. 407-408; Id., "Las colonias romanas...", art. cit., págs. 494-495; Id., "Aportaciones al proceso de romanización...", art. cit., pág. 371.

28 Vid., además en cuanto al nombre, A. HOLDER, Ait-Celtischer Sprachschatz, II, Leipzig, 1904, pág. 205.

29 Itineraria Hispana..., op. cit., pág. 246.

30 G. AlFÖDY, Römisches Städtewesen..., op. cit., págs. 31-32.

31 A. TOVAR, Iberische Landeskunde. Las tribus y las ciudades de la antigua Hispania. 3 , Tarraconensis, Baden-Baden, 1989, pág. 178. Semejante identificación es igualmente mantenida por G. ARIAS, vid., vgr., ME, 3, 1963, págs. 52, 58; $M E, 35,1991$, pág. 24; ME, 41, 1992, pág. 11.

32 Vid. J. SANCHEZ JIMENEZ, Excavaciones y trabajos arqueológicos en la provincia de Albacete de 1942 a 1946, Informes y Memorias, 15, Madrid, 1947, pág. 101; Id., "Inventario de los hallazgos monetarios en la provincia de Albacete". Anales del Sem. de H. a Arq. de Albacete, l, 1951, págs. 36, 38 y 46; A. BELTRAN, "Cabeza femenil de tipo claudiano en el Museo de Albacete", Anales del Sem. de H. ${ }^{\text {y }}$ Arq. de Albacete, I, 1951, págs. 19-21; AEArq., 30, 1957, págs. 116-117; J. SANCHEZ JIMÉNEZ, "Inventario de los hallazgos monetarios en la provincia de Albacete (cont.)", Publicaciones del Sem. de $H^{\circ}$ y Arq. de Albacete, 1962, pág. 108; véase también R. Sanz Gamo, "Lucernas romanas del Museo de Albacete", Anales del Centro de la UNED de Albacete, 4, 1982, pág. 206; Id., "Fuentes escritas sobre la Colonia Libisosa Forum Augustana (Lezuza)», Cultural Albacete, 35, 1989, págs. 10, 11 y 12; R. SANZ GAMO et alii, Las fibulas de la provincia de Albacete, Albacete, 1992, pág. 60; J.M. Abascal Palazon, R. Sanz Gamo, Bronces antiguos del Museo de Albacete. Albacete, 1993, págs. 18, 26, 104, 154 y 149; J.M. Noguera Celdoran, La escultura romana de la provincia de Albacete (Hispania Citerior-Conventus Carthaginensis), Albacete, 1994, págs. 90-95 y 168-9; R. SANZ GAMO, Cultura ibérica y romanización..., op. cit., págs. 78-81; 8. Gamo Parras, La antigüedad tardia en la provincia de Albacete, Albacete, 1998, págs. 138-139. 


\section{Parietinis}

Mencionada en esta vía del Itinerario de Antonino entre Libisosa de la que le separa XXII m.p., y Saltigi distante XVI m.p., medidas análogas con las que también aparece en los Vasos de Vicarello (I, II, III y IV). Para J. Lozano se ubicaría en Peñas de San Pedro quien afirma "En órden a Parietinis, nuestro pensamiento es que corresponde a la Villa de las Peñas. La distancia entre Libisosia y Parietinis, no desdice de la que reyna entre Lezuza, y las Peñas de San Pedro" "33. La misma opinión es compartida por J.A. Roa Erostarbe ${ }^{34}$. Sin embargo según E. Saavedra ${ }^{35}$ estaría "en Paerazos Viejos, término de Albacete, sobre la carretera de Úbeda", al igual que para A. Fernández Guerra ${ }^{36}$; también F. Coello ${ }^{37}$ la ubica en Paredazos, aun cuando para J.M. Roldán Hervás ${ }^{38}$ no está asegurada su identificación, al igual que para A. Tovar ${ }^{39}$. Posteriormente $P$. Sillières ha propuesto que las XXII m.p., distantes de Lezuza, llevan a localizar Parietinis en el cruce de la Cañada de Andalucía y la carretera de Albacete-Úbeda, en el lugar denominado Ventoro de la Vereda ${ }^{40}$, cerca de Los Paredazos, topónimo éste que por otra parte se corresponde muy significativamente con la palabra latina parietinae ${ }^{41}$.

\section{Saltici}

Es citada también por los Vasos de Vicarello (I: Saltigim; II, III y IV: Saltigi), y el Anónimo de Rávena $(313,13)$ con la forma de Saltis, constituyendo por

33 J. Lozano, Bastitania..., op. cit., disert. II, pág. 17. Sin embargo vid., la opinión de J.A Cean Bermúdez, Sumario..., op. cit., pág. 104.

34 J. Roa Erostarbe, Crónica..., op. cit., vol. II, pág. 364. Por el contrario vid., N. BLANCH Ė ILLA, Crónica..., op. cit., pág. 14: «Peñas de San Pedro... Esta villa, situada a la falda S. de un peñasco escarpado que forma el castillo de su nombre, han creido algunos sin fundamento ser la antigua Parietina, tercera mansión de Laminium a Caesaraugusta. Es indudable que en el sitio donde se eleva esta población existió una ciudad romana, aunque se ignora su nombre". Por su parte y en relación a Chinchilla vid., M. CORTÉS y LOPEZ, Diccionario geográfico-histórico..., op. cit., T. III, pág. 276; también P. MADOz, Diccionario geográfico-estadistico-histórico de España y sus posesiones de Ultramar, T. VII, Madrid, 1847, pág. 330.

35 E. SaAvedra, Discursos..., op. cit., pág. 100.

36 A. Fernandez GuerRa, Deitania y su cátedra episcopal de Begastro, Madrid, 1879, pág. 18

37 F. COEllo, "Vía romana...", art. cit., pág. 6.

38 Itineraria Hispana..., op. cit., pág. 257.

39 A. TovaR, Iberische Landeskunde..., op. cit., pág. 179: «Hay que suponerla a pocos kilómetros al O. O SE. de Albacete".

40 Vid.. P. SilliÉRES, "Le Camino de Anibal...", art. cit., pág. 75; Id., Les voies de communication..., op. cit., pág. 273; también G. ARIAS sigue idéntica localización vid., ME, 35, 1991, pág. 24; ME, 41, 1992, pág. 12.

Vid., RE, XVIII, 4, 1949, col. 1482; A. TovaR, Iberische Landeskunde..., op. cit., pág. 179; P. Silliéres, “Le Camino de Anibal...", art. cit., pág. 75; Id., Les voies de communication..., op. cit., págs. 273 y 801 . 
lo tanto, un cruce viario. Asimismo está atestiguada en Ptolomeo (II, 6, 60:

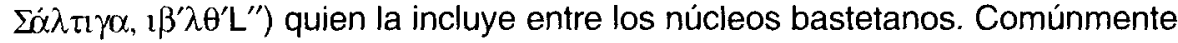
se viene localizando en torno a Chinchilla, ya desde J. Lozano ${ }^{42}$ para el que «nuestro cálculo lo está mirando en la posición de Chinchilla o sus contornos". Análoga localización es proporcionada por J.A. Ceán Bermú$\operatorname{dez}^{43}$, E. Saavedra ${ }^{44}$, A. Fernández Guerra ${ }^{45}, \mathrm{~F}$. Coello ${ }^{46}$, A. Schulten ${ }^{47}$, y K. Miller ${ }^{48}$. La misma identificación mantienen M. Corchado Soriano ${ }^{49}$, J.M. Roldán Hervás ${ }^{50}$, y A. Tovar ${ }^{51}$. Por su parte $P$. Sillières ${ }^{52}$, viene igualmente a confirmar dicha localización en Chinchilla, en donde según este autor, coincide la distancia por las fuentes itinerarias proporcionadas.

\section{VASOS DE VICARELLO}

Representan otra de las fuentes (CIL, XI, 3281-3284), para el conocimiento de la viaria romana del área objeto de estudio. Las mansiones de la vía descrita por esta fuente, relativas al ámbito de la provincia de Albacete, formaban parte según $P$. Sillières del denominado Camino de Anibal ${ }^{53}$, y son citadas de la forma siguiente:

20

$\begin{array}{ll}\begin{array}{l}\text { Libisosa } \\ \text { (Libisosam I) }\end{array} & \text { XXIII } \\ \text { Parietinis } & \text { XXII } \\ \begin{array}{c}\text { Saltigi } \\ \text { (Saltigim, I) }\end{array} & \text { XVI } \\ \text { Ad Palem (I) } & \text { XXXII }\end{array}$

(-en, II; -e, III; -ae, IV)

23

J. Lozano, Bastitania..., op. cit, disert. II, págs. 20 y ss.

J.A. Cean Bermudez, Sumario..., op. cit., pág. 496.

E. SaAvedra, Discursos..., op. cit., pág. 102.

A. Fernández Guerra, Discurso..., op. cit., págs. 122-123; Id., Deitania..., op. cit., pág. 18.

F. COELLO, “Via romana...", art. cit., pág. 6.

Vid., RE, I, 2, 1920, col. 2014.

Römische Reisewege..., op. cit., col. 175 y 181.

M. CoRchado Soriano, "Estudio sobre vias...», art. cit., pág. 151.

Itineraria Hispana..., op. cit., pág. 264.

A. Tovar, Iberische Landeskunde..., op. cit., pág. 167; véase tambièn al respecto G. ARIAS, ME, 35, 1991, pág. 24; $M E, 41,1992$, pág. 13.

52 P. Sil.lieres, "Le Camino de Anibal...", art. cit., pág. 76; Id., "Une grande route romaine menant à Carthagène: la voie Saltigi-Carthago Nova», MDAl(M), 23, 1982, pág. 247; Id., Les voies de communication..., op. cit., pág. 273.

53 Vid., P. Silliéres, “Le Camino de Anibal...", art. cit., págs. 31 y ss. 
Se trata, en efecto, de un tramo de la vía que enlazaba Castulo (Cazlona, Jaén) con Saetabis (Játiva), coincidiendo entre Libisosa (Lezuza) y Saltigi (Chinchilla) así como las medidas dadas entre mansiones, con la parte correspondiente de la vía 31 del Itinerario de Antonino Item a Laminio alio itinere Caesarea Augusta, anteriormente citada (It. Ant., 446, 11-447, 1-2). La ruta que atravesaba la provincia de oeste a este, tras dejar Villanueva de la Fuente en Ciudad Real, según $P$. Sillières ${ }^{54}$, se internaría en territorio albacetense en dirección hacia Viveros, llegando hasta Lezuza (Libisosa), y continuaria después hasta alcanzar Chinchilla (Saltigi) ${ }^{55}$. A partir de Saltigi, según Eduardo Saavedra ${ }^{56}$, la vía seguía más o menos rectilíneamente a través de Bonete y Almansa, opinión seguida por $M$. Corchado Soriano ${ }^{57}$. Sin embargo A. Fernández Guerra ${ }^{58}$ propondría una ruta más meridional por Pétrola, La Higuera y depresión de Caudete ${ }^{59}$. Por su parte y ya más recientemente $P$. Sillières ${ }^{60}$ ha podido confirmar, mediante fotografía aérea, este trazado meridional ${ }^{61}$ que desde Chinchilla (Saltigi) se dirigia hacia el sureste por Pétrola, La Higuera, Llano de la Consolación, Cerro de los Santos, Casa de Almansa, para seguir posteriormente hacia Fuente la Higuera, hasta llegar a Játiva (Saetabis).

\section{Mansiones}

Tan sólo nos ocuparemos de Ad Palem, por cuanto Libisosa, Parietinis y Saltigi-m (Saltici: It. Ant., 447, 2), han sido ya anteriormente tratadas.

\footnotetext{
54 lbid., págs. 61 y ss.

55 Para el tramo entre Chinchilla y Lezuza véase no obstante, P. SILLIERES, Les voies de communication..., op. cit., pág. 268.

56 Discursos..., op. cit., Madrid, 1862.

57 M. Corchado Soriano, “Estudio sobre vías...", art. cit., págs. 145-146.

58 A. Fernández Guerra, Discurso..., op. cit., págs. 122-6.

59 Véase también K. MiLler, Römische Reisewege..., op. cit., fig. 50, col. 177-8, y mapa de H. KIEPPER, en CIL, II, Supplem.

${ }_{60}$ P. Sillières, “Le Camino de Anibal...", art. cit., págs. 65 y ss.; Id., Les voies de communication..., op. cit., págs. 267 y ss.

61 No obstante sobre la revisión últimamente de algunos tramos de este trazado vid., G. Ponce Herrero, J.L. Simón Garcia, "Contribución al estudio del itinerario de la vía Augusta. Los

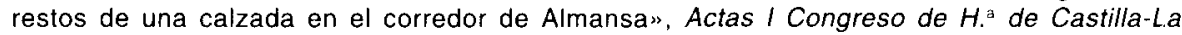
Mancha, T. IV, 1988, págs. 161-170; J. BLANQUEz PÉREZ, "La via Heraklea y el camino de Anibal. Nuevas interpretaciones de su trazado en las tierras del interior", Simposio sobre la Red Viaria en la Hispania Romana, Zaragoza, 1990 , págs. 65-76; también véase, F. Brotons et alii, "El tramo viario de Montealegre a Fuente la Higuera", Vias romanas del Sureste, Murcia, 1988, págs. 75-83; G. ARIAS, ME, 35, 1991, págs. 22-24; R. SANZ Gamo, Cultura ibérica y romanización..., op. cit., págs. 242-249.
} 
Ad Palem

Según se indica en los Vasos de Vicarello (II: Ad Palen; III: Ad Pale; IV: Ad Palae) distaba XXXII m.p., de Saltigi. Para E. Saavedra ${ }^{62}$ se situaría en "Nuestra Señora de Belén, legua y media al O. de Almansa". Por su parte $P$. Serrano Gómez ${ }^{63}$ la ubica próxima a Bonete, concretamente en Tesoro de Chavo, y K. Miller ${ }^{64}$ en Montealegre, mientras que según A. Tovar ${ }^{65}$ "Se puede suponer que, yendo en la misma dirección que la actual carretera de Alicante, podía estar poco antes de Almansa, al pie del Mugrón». Por otra parte, A. Fernández Guerra, partidario del trazado meridional, como ya se ha indicado ${ }^{66}$, para el tramo de la via que desde Saltigi (Chinchilla) se dirigía a Saetabis (Játiva), propondría la localización de dicha mansión junto al Cerro de los Santos ${ }^{67}$. Semejante ubicación ha sido posteriormente defendida por $P$. Sillières ${ }^{68}$, para quien el nombre mismo de la mansio, Ad Palem, resultaría muy significativo al encontrarse situada junto a un santuario dedicado a una deidad ibérica de la fecundidad, asimilada a la diosa romana Pales, protectora de pastizales y rebaños ${ }^{69}$.

\section{ANÓNIMO DE RÁVENA}

Junto al Itinerario de Antonino y los Vasos de Vicarello, el Ravennatis Anonymi Cosmographia o vulgarmente Anónimo de Rávena, viene a representar otra de las fuentes itinerarias antiguas de interés para la provincia de Albacete. Datada en el siglo $\mathrm{VII}^{70}$, no proporciona, no obstante, las distancias existentes entre las mansiones, limitándose tan sólo a consignar el nombre de éstas.

62 E. SaAvedra, Discursos..., op. cit., pág. 100.

63 P. Serrano Gómez, "La Plaine de la Consolation et la ville iberique d'Ello", BH, I, 1899. págs. $18-19$.

64 K. Millef, Römische Reisewege..., op. cit., col. 181.

55 A. Tovar, Iberische Landeskunde..., op. cit., pág. 179.

66 Véase notas $n .^{\circ} 58$ y 59.

67 A. FERnÁNDEZ GuerRA, Discurso..., op. cit., pág. 122: «Aquellos vasos argénteos, que se labraron hace diez y nueve siglos para uso y guía de caminantes, dan noticia de 112 paradas y de sus distancias, desde Cádiz á Roma; y todos ellos colocan á 32 pasos $(51,200 \mathrm{~m})$ SSE de Saltigi (Chinchilla) una estación, próxima á cierto lugar llamado Pale (que cada vaso itinerario escribe á su manera: Ad Pale, Ad Palae, Ad Palen, Ad Palem), frente por frente del Cerro de los Santos".

68 P. Sillières, "Le Camino...", art. cit, pág. 76; Id., Les voies de communication..., op. cit., pág. 272; véase también al respecto, G. ARIAS, ME, 35, 1991, pág. 24

69 Véase, P. Silliėres, Les voies de communication..., op. cit., págs. 808-810; cf., A. SCHULten, RE, XVIII, 3, 1949, col. 89.

70 Para cuestiones de cronología y carácter de esta obra vid., J.M. ROLdÁn HERvas, Itineraria Hispana..., op. cit., págs. 111 y ss. 
En la edición utilizada ${ }^{71}$, la parte contenida en esta obra, referente al área geográfica que nos ocupa, es descrita de la siguiente manera:

IV, 44

Iterum iuxta ipsam civitatem Complutum est civitas quae dicitur

Se trata de una parte del trazado de la vía ${ }^{72}$ que llegaba a poner en comunicación Complutum con Carthago Nova, conectando de esta manera el interior peninsular con el litoral. La ruta partía, en efecto, de Complutum importante núcleo desde el punto de vista de las comunicaciones hacia Caraca, siguiendo en dirección sur a través ya de la provincia de Cuenca ${ }^{73}$ por Uclés hacia Segobriga (Cabeza de Griego, Saelices), en donde se conservan importantes restos arqueológicos ${ }^{74}$, continuando hacia Alconchel hasta Pozo Amargo, en la que se viene tradicionalmente

\footnotetext{
71 Ravennatis Anonymi Cosmographia et Guidonis Geographica, Ed. M. PInder et G. PARTHEY, Aalen, 1860 (Reed. 1962).

72 Vid. F. COELLO, "Vías romanas de Sigüenza a Chinchilla", BRAH, 23, 1893, págs. 437 y ss.; J. Santa Maria, "Itinerarios romanos de la provincia de Cuenca", $B R A H, 31,1897$, págs. 5 y ss.; F. COELLO, "Caminos romanos de la provincia de Cuenca", BRAH, 31, 1897, págs. 19-25; A. Blazquez, musea, 40,1921, pág. 9; P. Beltrán Villagrasa, "Segóbriga", Archivo de Prehistoria Levantina, IV, 1953, pág. 22; M. Corchado Sorlano, El Priorato de Uclés, Madrid, 1965, págs. 61 y 78; Id., $M E, 10,1965$, pág. 261; G. ARIAS, ME, 9, 1965, págs. 220 y 222-223; M. Corchado Soriano, "Estudio sobre vías...", art. cit., págs. 143-144; M. Almagro Basch, Segóbriga. Guía del conjunto arqueológico, Madrid, 1978, pág. 24, y mapa pág. 20; J.M. ABASCAL Palazón, Vias de comunicación..., op. cit., págs. 77-84; M. Almagro BASCH, Segóbriga I. Los textos de la Antigüedad sobre Segóbriga y las discusiones acerca de la situación geográfica de aquella ciudad, Madrid, 1983, págs. 31 y 33; S. PALOMERo PlazA, "Las vias romanas de Segóbriga y su contexto en las vías romanas de la actual provincia de Cuenca", Homenaje al Prof. Martín Almagro Basch, T. III, Madrid, 1983, págs. 247 y ss.; Id., Las vias romanas..., op. cit., págs. 53 y ss.; G. ARIAS, Repertorio de caminos..., op. cit., págs. 371 y ss.; J. JORDAN MONTES, A. SELVA INIESTA, "Notas sobre la red viaria romana en la comarca de Hellin-Tobarra", Vias romanas del Sureste, Murcia, 1988. págs. 85-99; G. Carrasco SerRano, "Comunicaciones romanas de la provincia de Albacete en los itinerarios de época clásica", Al Basit, 23, 1988, págs. 41-42; F.J. López Precioso, "Vías romanas y visigodas del campo de Hellin», Antigüedad y Cristianismo, $X, 1993$, págs. 116 y ss.

73 Para el recorrido en la provincia de Cuenca vid., S. Palomero PLAZA, Las vias romanas..., op. cit, págs. 110-113.

74 Véase vgr., M. Almagro Basch, Segóbriga..., op. cit., Madrid, 1978.
} 
localizando Puteis ${ }^{75}$. Desde aquí la vía proseguía para entrar ya en la provincia de Albacete en dirección hacia La Roda, y llegar hasta Chinchilla (Saltigl). A partir de Chinchilla, el segundo tramo de la ruta, no atestiguado ya por el Anónimo de Rávena, según $P$. Sillières ${ }^{76}$ se dirigiría hacia Mercadillos al sur de Pozo Cañada, Tobarra y Tolmo de Minateda ${ }^{77}$, continuando hacia Cieza, en la provincia de Murcia, Alcantarilla y llegar por último a Cartagena.

Por otra parte, son diversos los miliarios que se atestiguan en esta vía ${ }^{78}$, perteneciendo algunos de ellos al ámbito objeto de estudio. Éste

75 Puteis es identificada con la Ad Putea de it. Ant., 447, 3, por M. Almagro Basch, Segóbriga..., op. cit., mapa pág. 20, y J.M. Abascal Palazón, Vias de comunicación..., op. cit., págs. 74, 82 y 84; también al respecto vid., J.M. RoldÁn HeRvás, Itineraria Hispania..., op. cit., pág. 261. Asimismo en MJSEA, 40, 1921, pág. 9 se afirma: "La situación de Ad Putea en las inmediaciones de Pozo Amargo resulta comprobada por el mismo señor Coello y por los restos de una vía romana, que describe el Ravenate (siglo VII), la cual partía de Compluto (Cerro de San Juan del Viso, cerca de Alcalá de Henares) y pasaba por Caraca (Carabaña), Segobrina (ruinas junto a Sahelices), Puteis (Pozo Amargo) y Saltici». Sin embargo en contra de esta opinión véase, $S$. Palomero Plaza, Las vias romanas..., op. cit., págs. 158-159.

76 P. Sitlieres, “Une grande route...", art. cit., págs. 253-255; Id., Les voies de communication..., op. cit., págs. 384 y ss.

77 Según P. SilliéRES la ruta se dirigía desde Tobarra hasta el Tolmo de Minateda, sin pasar por Hellin, vid., "Una grande route...", art. cit., pág. 255, y Les voies de communication..., op. cit., pág. 388. Además este mismo autor, propuso situar la llunum de Ptolomeo (II, 6, 60) y la $/ y y u(h)$ de Al-'Udri en este importante enclave del Tolmo de Minateda, vid., Les voies de communication..., op. cit., pág. 389: "Aussi préférons-nous situer flunum et lyyuh au Tolmo de Minateda: cet extraordinaire piton rocheaux se dresse en effet au milieu de la vallée de la Rambla de Tobarra, c'est-à-dire exactament sur le tracé de la route antique. En outre, il a fourni de nombreux temoignages d'une longue occupation qui s'y est maintenue depuis le milieu du premier millénaire avant Jésus-Christ jusqu'au Bas Empire et même jusqu'au début de l'occupation musulmane". En este mismo sentido y más recientemente cf., L. ABAD CASAL et alii, "El Proyecto de investigación arqueológica Tolmo de Minateda (Hellin-Albacete): Nuevas perspectivas en el panorama arqueológico del sureste peninsular", Jornadas de Arqueología Albacetense en la Univ. Autónoma de Madrid, 1993, págs. 145176; L. Abad CASAL, C. Aranegul Gasco, «Las ciudades romanas de los ámbitos baleárico y levantino", La ciudad hispanorromana, Barcelona, 1993, pág. 104; L. ABAD CASAL, «Algunas novedades onomásticas de la ciudad de llunum (El Tolmo de Minateda, Hellin, Albacete)", Antigüedad y Cristianismo, X, 1993, págs. 133-138; Id., "La epigrafia del Tolmo de Minateda (Hellín-Albacete) y un nuevo municipio romano del conventus Carthaginensis", AEArq., 69, 1996, págs. 77-108; L. abad Casal, S. Gutierrez Lloret, "lyih (El Tolmo de Minateda, Hellín, Albacete). Una civitas en el limes visigodo-bizantino", Antigüedad y Cristianismo, XIV, 1997, págs. 598-599.

78 Se tiene referencia hasta el momento actual de 15 miliarios para esta via. Para el tramo Carthago Nova-Saltigi vid., P. SilliéRES, “Une grande route...", art. cit., págs. 247-251; Id., Les voies de communication..., op. cit., págs. 120-127; en relación a la provincia de Cuenca, $S$. PAlOMERo PlazA, "Las vías romanas de Segóbriga...". art. cit., págs. 247-262; Id., Las vias romanas..., op. cit, págs. 77-81; para el miliario de Los Pontones en la provincia de Albacete y el resto también de los de dicha provincia, J.M. ABASCAL PALAZON, Inscripciones romanas..., op. cit., págs. 83-88. En general puede verse asimismo, J. Lostal Pros, Los miliarios de la provincia Tarraconense, Zaragoza, 1992. También recientemente al respecto, J.M. ABASCAL, A.J. LORRIO, “EI miliario de Tiberio de Segóbriga y la via Complutum-Carthago Nova". Homenaje al Profesor Montenegro. Estudios de Historia Antigua, Valladolid, 1999, págs. 561-568. 
es el caso del descubierto en 1978, a unos $700 \mathrm{~m}$ al oeste de Torre Uchea, junto al Camino Viejo de Murcia, y cuyo texto según P. Sillières ${ }^{79}$ es el siguiente:

[I]m[p(erator) Caesar C(aius) lulius / Verus] Ma[ximi]nus, p(ius), / [f(elix), Aug(ustus)], Germ(anicus) m[ax(imus), Daci]c(us) max (imus), [Sarm(aticus) max(imus)], / pontif(ex) max(imus), [trib(unicia) / pot] est(ate) v, imp(erator) vii, $p$ (ater) [p(atriae), c[o(n)s(ul), / [proco(n)s(ul) et] C(aius) lul(ius) Verus M[axi]mus, / [nobilissimus Caes (ar) ...

De la zona de Pozo Cañada proceden asimismo tres miliarios, el primero de los cuales fue descubierto a finales del siglo XIX, exactamente en 1890 , en Venta Nueva, y se corresponde a Tiberio, habiendo sido publicado por C. Dubois ${ }^{80}$ a comienzos de siglo. P. Sillières ${ }^{81}$ ofrece así su texto:

[Ti(berius) Caesar], divi Aug(usti) f(ilius), / [divi lul(i) ne]p(os, Aug(ustus), pont(ifex) / [max(imus), co(n)]s(ul) v, imp(erator) [viii, - - - .

También de Pozo Cañada se conoce otro miliario, hallado en Venta Nueva, cuya cronología puede situarse según $P$. Sillières ${ }^{82}$ hacia el año 98 d.C., presentando el siguiente texto, según dicho autor:

Imp(erator) Caesar Ne[rva] / Traian[u]s Aug(ustus) Ge[rm(anicus)] / pont(ifex) max(imus) tri(bunicia) po[t(estate) II] / [c]o(n) s(ul) II....

79 P. SILLIÉRES, «Une grande route...», art. cit., págs. 250-251; Id., “Les milliaires du sud de la Péninsule lbérique", Epigraphie Hispanique, Paris, 1984, pág. 277, n. ${ }^{\circ} 64$; Id., Les voies de communication... op. cit., págs. 123-124; AE, 1982, pág. $159,{ }^{\circ}{ }^{\circ} 624$; según P. SILI.IĖEES, dicho miliario se enmarca cronológicamente a finales de la época de Maximino. Veáse tainbién J.M. Abascal Palazón, Inscripciones romanas..., op. cit., págs. 87-88; J. Lostal Pros, Los miliarios..., op. cit., págs. 113-4, . $^{\circ} 110$.

B0 C. DuBors, “inscriptions romaines d'Espagne», $B H_{,} 3,1901$, pág. 212:

DIVI.AVG.F

P.AVG.PONT [NT liés]

$S V \cdot I M P$

[Tib. Caes] Divi Aug(usti) f(ilius)

[divi ne]p(os, Aug(ustus) Pont(ifex)

[Maximus Con]s(ul) V. Imp(erator), etc...

8t P. SILLIERES, "Une grande route...", art. cit., pág. 250 ; Id., "Les milliaires du sud...", Epigraphie Hispanique, París, 1984 , pág. 277 , n. ${ }^{\circ} 65$; Id., Les voies de communication..., op. cit., págs. 124-125; J.M. Abascal PALAzón, Inscripciones romanas..., op. cit., pág. 87; J. Lostal Pros, Los miliarios..., op. cit, págs. 49-50, n. 42.

82 Vid., P. SILLIĖRES, "Trois nouveaux milliaires du sud de l'Espagne», XV CNA (Lugo, 1977), Zaragoza, 1979, págs. 1076-1078; Id., "Les milliaires du sud...", Epigraphie Hispanique, Paris, 1984, pág. 277, n. ${ }^{\circ} 66$; ld., Les voies de communication..., op. cit., págs. 125-126; AE, 1982, pág. 158, n. ${ }^{\circ}$ 621; véase también R. SANZ GAMO, "Avance para un estudio de la epigrafia romana en la provincia de Albacete", Anales de la UNED de Albacete, 1, 1979, pág. 170, fig. 4; J.M. ABASCAL PALAZON, inscripciones romanas..., op. cit., pág. 86; J. Lostal PRos, Los miliarios..., op. cit., pág. 78, . $^{\circ} 74$. 
El tercer miliario procedente de esta misma zona, fue descubierto en 1976 al sureste de Pozo Cañada, exactamente en el paraje denominado EI Estrecho. La interpretación de su texto, pese a su carácter fragmentario, es propuesta por $P$. Sillières ${ }^{83}$ de la manera siguiente:

[Imp(eratori) Caes(ari / divi Severi Pii filio / divi Marci Antonini nepoti / divi Antonini Pii pronepoti / divi Hadriani abnepoti / divi Traiani P]ar[thici et / divi Nervae] ab[nepoti / M. Aurelio An]ton [ino / pio felici] Au[g(usto) Parthico / max(imo) Britannico] max (imo) [Germa / nico max(imo) pon]tifi[ci max(imo)...

A esta vía pertenece igualmente el miliario de Los Pontones, descubierto a unos $20 \mathrm{~km}$ al norte de Albacete ${ }^{84}$. La restitución de su texto propuesta por J.M. Abascal Palazón ${ }^{85}$ sería:

$$
\begin{aligned}
& \text { Ti(berius) Cae[sar] d[ivi Aug(usti) f(ilius)] } \\
& \text { divi I[uli] n(epos) [Aug(ustus) pont(ifex)] } \\
& \text { max(imus) [co(n)s(ul) } V \text { [imp(erator) VIII] } \\
& \text { trib(unicia) p[ot(estate)] X[XXIII o XXXIIII] } \\
& \text { [(milia passum) ---] }
\end{aligned}
$$

Esta serie de miliarios constituyen, por lo tanto, testimonios de primer orden en relación a esta ruta Complutum-Carthago Nova, destacable eje de penetración de influencias hacia la Meseta ${ }^{86}$.

Pero a estas vías, hay que agregar otras no atestiguadas en las fuentes antiguas itinerarias - como es el caso de la ruta Corduba-Saguntum-, y cuyo estudio arqueológico detallado y riguroso, permitirá ir completando el conocimiento del sistema de comunicaciones en época romana de este ámbito territorial, cuya situación ${ }^{87}$ le convertiría en área de paso entre la costa, la Meseta y la Alta Andalucía.

83 P. SilliERES, “Tres nouveaux milliaires...”, XV CNA (Lugo, 1977), Zaragoza, 1979, págs. 1078-1081; Id., “Les milliaires du sud...”. Epigraphie Hispanique, Paris, 1984, pág. 277, n. ${ }^{\circ} 67$; Id., Les voies de communication..., op. cit., págs. 126-127; AE, 1982, pág. 158, n. ${ }^{\circ} 622$; según $P$. Sillières este miliario podria enmarcarse en época de Caracalla. Véase también J.M. ABASCAL PALAzON, Inscripciones romanas..., op. cit., pág. 85; J. Lostal Pros, Los miliarios..., op. cit., págs. 101-2, n. 99.

${ }_{84}$ Vid., NAH, II, 1-3, 1953, pág. 207.

85 J.M. ABASCAL PALAZON, Inscripciones romanas..., op. cit., págs. 83-85; AE, 1990, pág. 177. n. ${ }^{\circ} 625$; HEp., 4, 1994, pág. 26, n. ${ }^{\circ} 19 .$.

86 Vid., P. Sillières, Les voies de communication..., op. cit., pág. 383.

87 El carácter del territorio provincial de Albacete como cruce de vías, determinará que en torno a ellas se asienten toda una serie de núcleos de poblacion, vid., y sobre el poblamiento romano en este ámbito, G. Carrasco SerRano, «Aportación al análisis del poblamiento romano de la provincia de Albacete», Caesaraugusta, 71, 1995, págs. 241-255; Id., "La ocupación del territorio provincial de Albacete en época romana: ciudades y villae", Homenaje al Profesor Montenegro. Estudios de Historia Antigua, Valladolid, 1999, págs. 521-529; Id., "Notas sobre el poblamiento romano en el ámbito provincial de Albacete", Actas // Congreso M. de Albacete, 2000 (en prensa). 


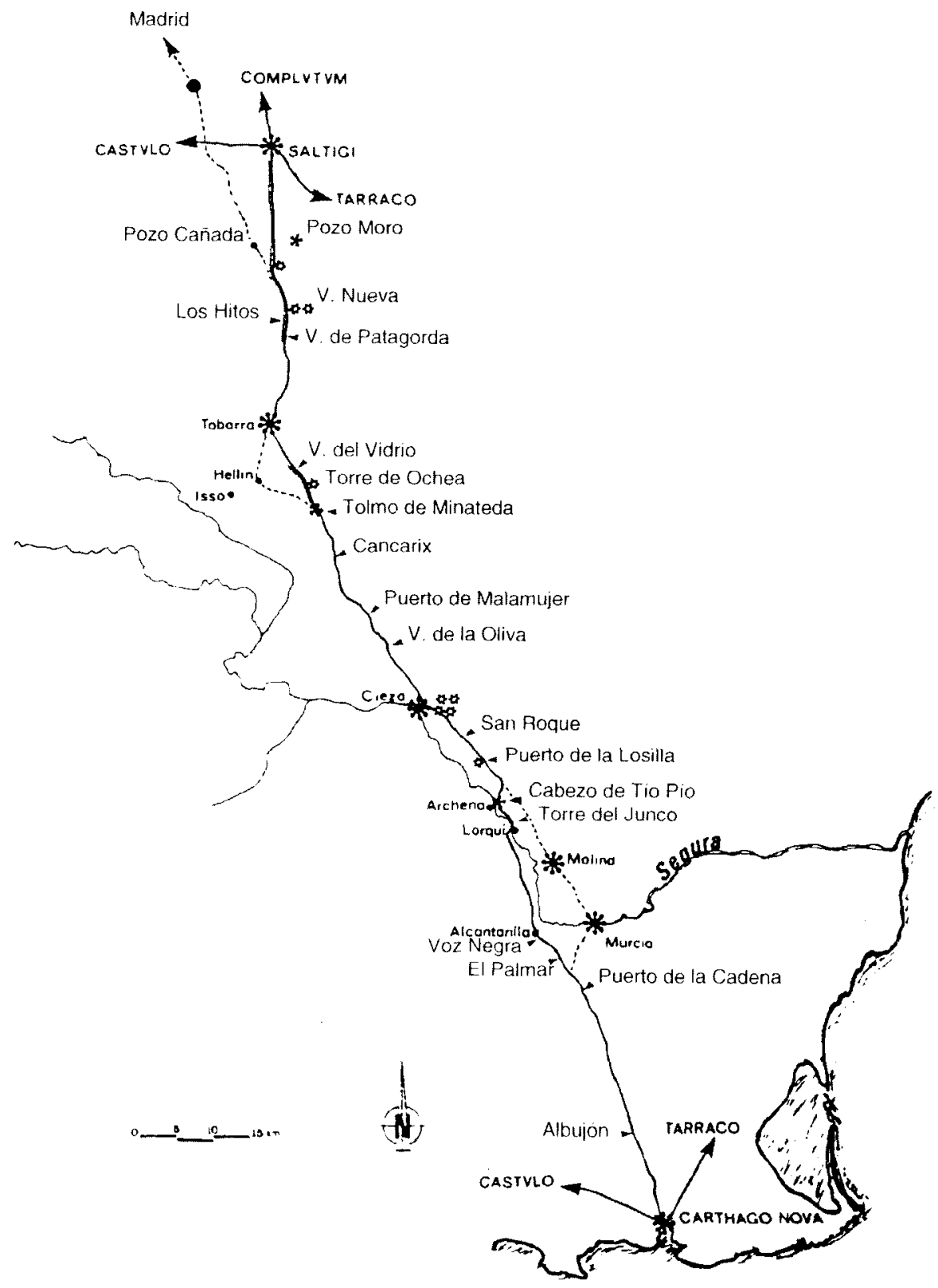

Trazado de la vía romana de Saltigi a Carthago Nova según $P$. Sillières. 